\title{
Nutritional Support Improves Outcome in Patients with Lung Cancer Cachexia Receiving Chemotherapy
}

\author{
PS AKHTAR $^{\mathrm{a}}, \mathrm{N} \mathrm{KHATUN}^{\mathrm{b}}, \mathrm{R}^{\text {PARVEEN }}{ }^{\mathrm{c}}, \mathrm{R}$ ISLAM $^{\mathrm{d}}, \mathrm{FARA}^{\mathrm{e}}$
}

\begin{abstract}
Summary:
Background: Malnutrition is a frequent complication in patients with advanced staged lung cancer and can negatively affect the outcome of treatments. Lack of knowledge about nutrition, complications of disease and side effects of anticancer therapies can also lead to inadequate nutrient intake and subsequent malnutrition. Nutritional status is a strong predictor of quality of life in cancer patients.
\end{abstract}

Objective: To get the effect of the nutritional intervention on outcome of dietary intake, body composition, nutritional status, functional capacity and quality of life in patients with lung cancer cachexia receiving chemotherapy.

Patients and Methods: This 6 months study included the lung cancer patients who were interviewed with clinical assessment. Nutritional score of each patient was recorded. Individualized management plan with nutritional intervention was given and nutritional counseling was done by a nutritionist every week. Chemotherapy \pm radiotherapy was given. Every patient was followed up at $1^{\text {st }}, 2^{\text {nd }}, 3^{\text {rd }}$ and $6^{\text {th }}$ week and was assessed regarding symptoms, clinical findings, nutritional score and radiological status.

\section{Introduction:}

Malnutrition represents a risk factor for poor prognosis among patients with cancer, affecting up to

a. Prof. Parveen Shahida Akhtar, Professor and Departmental Head, Dept. of Medical oncology, National Institute of cancer Research \& Hospital, Dhaka

b. Dr. Nazreena Khatun, Assistant Professor, Dept. of Medical oncology, National Institute of Cancer Research \& Hospital, Dhaka

c. Dr. Rahnuma Parveen, Medical Officer, Dept. of Medical oncology, National Institute of Cancer Research \& Hospital, Dhaka

d. Dr. Rafiqul Islam, Medical Officer, Dept. of Medical oncology, National Institute of Cancer Research \& Hospital, Dhaka.

e. Dr. Ferdous Ara, Medical Officer, Dept. of Medical oncology, National Institute of Cancer Research \& Hospital, Dhaka.

Address of Correspondence: Parveen Shahida Akhtar, Professor and Departmental Head, Dept. of Medical oncology, National Institute of cancer Research \& Hospital, Dhaka, E-mail: sharti_oncology @yahoo.com, Mobile: 01711622788

Received: 12 November, 2017

Accepted: 25 December, 2018
Results: Total 628 lung cancer patients with 523 (83\%) males and 105 (17\%) females (Male: female 4.98:1) were enrolled. Mean age was 56.88 years. Two thirds of them were illiterate. Around $90 \%$ came from poor and below average socioeconomic group. More than $95 \%$ male and $>66 \%$ female were tobacco users in different forms. On assessing nutritional score, almost all were with high risk score (95\%). About $80 \%$ presented with $\mathrm{WHO}$ performance status at 2 and 3. About $61 \%$ patients got treatment after hospitalization. Following nutritional intervention along with supportive, symptomatic, treatment of comorbid diseases and anti-cancer treatment, the result showed that mean nutritional score at $1^{\text {st }}$ and $2^{\text {nd }}$ week were 8.24 and 6.63 (high risk), at $3^{\text {rd }}$ and $6^{\text {th }}$ week were 5.46 and 4.34 (Intermediate risk). There was a significant effect for time $(p<001)$. Symptomatic improvement occurred in $60 \%$ of the patients. Conclusion: Nutritional intervention improves nutritional score if the other treatment like supportive, symptomatic, comorbid condition and anticancer treatment could be applied adequately.

(J Bangladesh Coll Phys Surg 2019; 37: 66-71)

DOI: https://doi.org/10.3329/jbcps.v37i2.40562

$85 \%$ of patients with certain cancers ${ }^{1}$. Patients with cancer of the lung, esophagus, stomach, colon, rectum, liver, and pancreas are at greatest risk ${ }^{2}$.

Poor nutritional status, weight loss, and malnutri-tion lead to poor outcomes for patients, in terms of quality of life, functional status, compli-cation rates, and treatment disruptions $\mathrm{s}^{3,4,5}$; and for some patients, cancer cachexia $^{6}$. The prevalence is higher in patients with lung and gastrointestinal tumors ${ }^{7,8}$. At the time of diagnosis, $60 \%$ of patients with lung cancer have already experienced a significant weight loss ${ }^{9}$. In patients receiving palliative chemotherapy, weight loss predicts a significantly shorter survival and poorer quality of life $^{3}$. One known reason for poorer outcomes in patients with lung cancers (non- small cell) with weight loss are a reduced response to chemotherapy as well as increased toxicity from treatment ${ }^{10}$. The prevention and early detection of malnutrition, with early nutritional intervention for patients can improve 
patients' nutritional status and help patients to maintain body weight, maintain lean body mass, better tolerate treatment, and im-prove quality of life $6,11,12-15$.

According to the Hospital Cancer Registry Report of National Institute of Cancer Research \& Hospital (NICRH), Dhaka, Bangladesh, in 2010, the lung cancer is the most common cancer (31.4\%) among the male cancer patients $^{16}$. In the year of 2013 highest number of lung cancer patient $(30.5 \%)$ attended medical oncology department of NICRH. Of them, almost all were symptomatic and $80 \%$ presents with weight loss (from registry book of medical oncology department, NICRH, 2013). One important cause of poor nutritional status in these patients is lack of education and lack of proper knowledge and awareness about nutrition and nutritional value of easily available, cheap and homemade common foods.

This provided a rationale to investigate whether nutritional intervention including regular nutritional counseling to increase food intake, modification of the energy density of meals, prescription of oral nutritional supplements and relief of symptoms that causes reduced food intake could improve the nutritional status of patients and clinical outcomes.

\section{Patients and Method:}

This experimental and analytic study was carried out on adults with histologically proven, metastatic or locally advanced lung cancer if they had lost any weight in the 3 months before presentation. The lung cancer patients who agreed to undergo palliative chemotherapy and were fit for chemotherapy according to standard local criteria were selected for the study.

Both male and female patients with age below 75 years were included in the study, with normal liver and kidney function. Exclusion criteria were age above 75 yrs, previously treated patients, unconscious patients, ischemic heart disease with ejection fraction $<45 \%$, SGPT level $>3$ times of normal value, Alkaline phosphatase 4 times of normal value, creatinine clearance $<45 \mathrm{ml} /$ minute.

All patients provided written informed consent before study entry. The study was approved by the Ethical Committee of NICRH.

The patients were recruited for the study from January 2013 to June 2013. Each patient was interviewed and clinical assessment was being done. Nutritional score of each patient was recorded according to nutritional risk score.

Individualized management plan was taken for every patient to meet their nutritional demand, for pain relief, treatment of disabling symptoms and associated secondary infections and co morbidities. Nutritional counseling was done by a nutritionist every week in presence of a medical oncologist for each patient. Nutritional intervention was given by oral high calorie diet. Supplementary medicine such as appetizer, iron, vitamin, minerals, amino acid, albumin, fat, carbohydrate and water was given by oral, enteral and parental route. Correction of hematological, biochemical deficit, other symptoms management along with management of co morbidities and psychological support was given side by side. The patients were managed both outdoor and indoor basis. Chemotherapy \pm radiotherapy was given as per tumor board decision.

Every patient was followed up at $1^{\text {st }}, 2^{\text {nd }}, 3^{\text {rd }}$ and $6^{\text {th }}$ week and was assessed regarding symptoms, clinical findings, nutritional score and radiological status. All the findings were recorded. Data were analyzed by SPSS (Version-12).

\section{Result:}

Total 628 (105 female and 523 male) lung cancer patients were enrolled with a male-female ratio of 4.98:1 and mean age of 56.88 years. Sixty eight percent of the patients could not read and write, about $20 \%$ had primary education. Around $90 \%$ of them came from poor and below average socioeconomic group. Among the male patients, $>95 \%$ were tobacco user either in the form of smoking, gul or with betel nut or combination of them. In case of female patients, $>66 \%$ were tobacco user, mostly in the form of tobacco leaf with betel nut or gul.

Most common histopathology was squamous cell carcinoma $(40 \%)$, then adenocarcinoma (37\%) and small cell carcinoma (15\%). Common presentation of the lung cancer was cough (96\%), weakness (82\%), anorexia $(81.8 \%)$, chest pain $(56.4 \%)$, and insomnia $(33 \%)$.

Forty two percent of the patients were with comorbid diseases such as diabetes mellitus, hypertension, 
ischemic heart disease, COPD etc. On assessing nutritional score, almost all were with high risk score (95\%). About $80 \%$ of the lung cancer patients presented with WHO performance status at 2 and 3. About $61 \%$ patients got treatment after hospitalization.

For nutritional intervention along with supportive, symptomatic, treatment of comorbid diseases and anti cancer treatment, the attendance of the patients at $1^{\text {st }}$ week was $98.43 \%, 2^{\text {nd }}$ week $96.18 \%, 3^{\text {rd }}$ week $85.36 \%$ and at $6^{\text {th }}$ week $75 \%$.

The result showed that mean nutritional score at $1^{\text {st }}$ week was 8.24 (high risk), $2^{\text {nd }}$ week 6.63 (high risk), $3^{\text {rd }}$ week 5.46 (intermediate risk) and at $6^{\text {th }}$ week 4.34 (Intermediate risk).

\section{Table-I}

\begin{tabular}{lcc}
\multicolumn{2}{c}{$\begin{array}{c}\text { Descriptive statistics for different follow up } \\
\text { nutritional score }\end{array}$} \\
Follow up times & $\begin{array}{c}\text { Mean Nutritional } \\
\text { Risk Score }\end{array}$ & $\begin{array}{c}\text { Standard } \\
\text { Deviation }\end{array}$ \\
\hline $1^{\text {st }}$ week & 8.24 & 2.330 \\
$2^{\text {nd }}$ week & 6.63 & 2.231 \\
$3^{\text {rd }}$ week & 5.46 & 2.302 \\
$6^{\text {th }}$ week & 4.34 & 2.067 \\
\hline
\end{tabular}

A one-way repeated measures ANOVA was conducted to compare Nutritional risk scores on the four follow up times. There was a significant effect for time, Wilks' Lamda $=.064, \mathrm{~F}(2,564)=2246.07, \mathrm{p}<.001$, multivariate partial eta squared $=.936$. Symptomatic improvement occurred in $60 \%$ of the patients.

\section{Appendix I}

Nutritional Risk Score

[Source: Summerton C, Shetty P, Sandle LN, Watt S. Nutritional, metabolic and environmental disease. Chapter 10.Davidson's Principles \& Practice of Medicine, $19^{\text {th }}$ edition: 2002, Elsevier science, Churchill Livingstone.]

Criterion

Score

Patient's score

\section{Weight loss in last 3 months (unintentional)}

No weight loss

0-3 kg weight loss

3-6 kg weight loss

$>6 \mathrm{~kg}$ weight loss

0
1
2
3

\section{BMI (weight/height ${ }^{2}$ )}

$>20$

$18-19$

$15-17$

$<15$

(1)

\section{Appetite}

Good (manages most of the three meals per day) 0

Poor (Leaves more than half of the meals provided) 2

Nil or virtually nil

4.Ability to eat and retain food

No difficulties; no diarrhea; no vomiting 0

Problems handling food: mild diarrhea or vomiting 1

Difficulty in swallowing or chewing: moderate diarrhea or vomiting 2

Unable to take food orally; severe diarrhea; severe vomiting 3

\section{Stress factor}

No stress factor

Mild (minor surgery, infection)

Moderate (Chronic disease, major surgery)

Severe (Multiple injuries, severe sepsis, cancer) 3

Total score

Maximum score $=15$; Minimum score $=0$

High risk $=6-15 ;$ Intermediate risk $=4-5$; Low risk $=0-3$ 


\section{Appendix II}

\section{WHO performance status scores}

- 0 -Asymptomatic (fully active, able to carry on all pre-disease activities without restriction).

- 1 - Symptomatic but completely ambulatory (restricted in physically strenuous activity but ambulatory and able to carry out work of a light or sedentary nature; for example, light housework, office work).

- 2 - Symptomatic, $<50 \%$ in bed during the day (ambulatory and capable of all self-care but unable to carry out any work activities; up and about more than $50 \%$ of waking hours).

- 3 - Symptomatic, $>50 \%$ in bed, but not bedbound (capable of only limited self-care, confined to bed or chair $50 \%$ or more of waking hours).

- 4 - Bedbound (completely disabled, cannot carry on any self-care, totally confined to bed or chair).

- 5 - Death.

\section{Discussion:}

Prevalence of malnutrition in lung cancer patients was found to be $45 \%$ in a study: but it is $73 \%$ with metastatic cancer ${ }^{17}$. Consequences of malnutrition include not only increased risk of infections, poor wound healing, decreased quality of life and transfer to higher level care ${ }^{12}$, but a significant emotional burden, anxiety and hopelessness also ${ }^{18}$.

DeWys and colleagues found that as little as 5\% weight loss predicted decreased response to therapy ${ }^{3}$. They also found that overall survival rates, performance status, produc-tivity, and quality of life declined concurrently with weight $\operatorname{loss}^{3}$. Early recognition and detection of risk for malnutrition through nutrition screening followed by comprehensive assessments is increasingly recognized as imperative in the development of standards of quality of care in oncology practices ${ }^{19}$. Several screening tools have reported their diagnostic accuracy.

In this study, majority of the study population were illiterate, representing poor and below average socioeconomic group. For this reason an easy but text book approved nutritional risk score had been used for initial assessment and clinical outcome following nutritional intervention.

Another big issue was the patients' lack of knowledge about nutrition and even about their disease. So the goal of this study was to improve the nutritional knowledge by giving proper education regarding their disease condition and nutritional counseling emphasizing the importance of nutritional improvement.

About $61 \%$ patients got treatment after hospitalization. For nutrient rich dietary advice, easily available, homemade and low cost diets had been chosen so that all the patients can follow the diet chart. The patients were offered 'rice starch' (the liquid which is usually poured off after boiling rice in Bangladesh) when admitted in hospital and also advised to take three to four glass of it at home. It is a nutrient rich fluid containing carbohydrates, protein, minerals and vitamins. The nutritionist supplied the appropriate diet chart for individual patient with proper dietary advice. The patients were interviewed in every follow up regarding their food intake and assessment of level of knowledge of nutrition.

All the interventions caused significant improvement in food intake, performance status and body weight, which were scored according to nutritional risk score and the final score after six weeks intervention showed significant improvement in nutritional status, mean nutritional risk score from 8.24 in $1^{\text {st }}$ week declining to 4.34 in $6^{\text {th }}$ week. This improvement was found statistically significant $(\mathrm{p}<.001)$.

One small Australian study has shown similar significant improvement in outcome after nutritional intervention in cancer patients. Along with chemotherapy, nutrition counseling and use of an oral nutritional supplement resulted in improvements in nutritional status, Karnofsky performance status, lean body mass and quality of life in patients with non-small cell lung or pancreatic cancer ${ }^{20}$. There are some other studies which have shown improvement in clinical outcome after nutritional intervention.

Many of these studies found improved immediate or patient-centered outcomes in the nutrition intervention groups. The two Randomized Controlled Trials $(\mathrm{RCT})^{21,22}$ that measured dietary intake both found 
significant increases in the intervention groups. This was also reported in the positive-quality systematic review $^{23}$ on the effect of oral nutrition support or enteral tube feeding versus routine care in patients undergoing chemotherapy or radiation therapy, which reported a significant increase in total dietary energy intake. Two level II studies ${ }^{24,25}$, a level III- $3^{25}$ and level $\mathrm{IV}^{26}$ study found that the intervention group increased their weight. In the pseudo-randomized trial by Brown et al..$^{27}$ (level III-1) in an outpatient rural oncology setting in Australia, there were clinically significant improvements in nutritional status as measured by Subjective Global Assessment (SGA) in the intensive intervention group.

A level III-1 study ${ }^{28}$ (post hoc analysis) found significantly greater survival and quality of life (QoL) in patients who maintained their weight versus those who lost weight during an RCT of nutrition intervention comparing a fish oil-enriched supplement with a traditional supplement.

Dietary counseling by a dietician and/or oral nutritional supplements are effective methods of nutrition intervention and have been found to improve dietary intake, nutritional status and quality of life in patients receiving radiotherapy (NHMRC grade of recommendation $\mathrm{A})^{29}$. There were five RCTs in chemotherapy, which found improvements in nutritional outcomes but not patient-centered outcomes such as QoL or survival ${ }^{29}$.

Although the significant improvement in clinical outcome after nutritional interventions are nutritional risk score based in this study, it will act as a baseline for further evaluation and quantitative study to prove this primary findings in future and establish the need for nutritional intervention during cancer treatment for better outcome.

\section{Conclusion:}

Nutritional intervention including proper nutritional counseling improves nutritional score and thereby clinical outcomes if the other treatment like supportive, symptomatic, co morbid condition and anticancer treatment could be applied adequately. However further well designed large scale studies are required to establish significant improvement in quality of life and treatment outcome.

\section{Funding}

This work was funded by the Directorate General of Health Service (DGHS) under Health, Population and Nutrition Sector Development Program (HPNSDP).

\section{Acknowledgements}

The authors would like to thank the Ministry of Health and Family Welfare for sponsoring the study, the director of NICRH and Ethical Review committee for approving the study, nutritionist Hosne Ara, Dr. Md. Johirul Islam for statistical analysis, and all the physicians and working staffs of the department of Medical Oncology, NICRH for their continuous support and inspiration to complete the study successfully.

\section{References:}

1. Fatma CBA, Hanène BS, Najiba C, Marwa F, Amel C, Sofia T, et al. Assessment of nutritional status in patients with primary lung cancer. La Tunisie Médicale 2013; 91 (10): 600-4.

2. Capra S, Ferguson M, Ried K. Cancer: impact of nutrition intervention outcome-nutrition issues for patients. Nutrition. 2001; 17:769-772.

3. DeWys WD, Begg C, Lavin PT, Band PR, Bennett JM, Bertino JR et al. Prognostic effect of weight loss prior to chemotherapy in cancer patients. Am J Med. 1980; 69:491-497.

4. Andreyev JHN, Norman AR, Oates J, Cunningham D. Why do patients with weight loss have a worse outcome when undergoing chemother-apy for gastrointestinal malignancies? Eur J Cancer. 1998; 34:503-509.

5. Marin Caro MM, Laviano A, Pichard C. Nutritional intervention and quality of life in adult oncology patients. Clin Nutr. 2007; 26:289-301.

6. Fearon K, Strasser F, Anker SD Bosaeus I, Bruera E, Fainsinger $\mathrm{RL}$, et al. Definition and classifica-tion of cancer cachexia: an international consensus. Lancet Oncol. 2011; 12:489-495.

7. Muscaritoli M, Bossola M, Aversa Z, Bellantone R,. Rossi Fanelli F. Prevention and treatment of cancer cachexia: new insights into and old problem. Eur J Cancer 2006; 42:31-41

8. MacDonald N, Easson AM, Mazurak VC, Dunn GP, Baracos VE . Understanding and managing cancer cachexia. J Am Coll Surg 2003; 197:143-161.

9. Bruera E. ABC of palliative care. Anorexia, cachexia, and nutrition. BMJ 1997; 315 (7117): 1219-22.

10. Ross PJ, Ashley S, Norton A, Priest K, Waters JS, Eisen T, et al. Do patients with weight loss have a worse outcome when undergoing chemotherapy for lung cancers? Br. J. Cancer 2004; 90: 1905-1911.

11. Watterson C, Fraser A, Banks M, Isenring E, Miller M, Silvester C. et al., Evidence based practice guidelines for the nutritional 
management of malnutrition in adult patients across the continuum of care. Nutrition and Dietetics 2009; 66 (Suppl 3): S1-S34.

12. Nayel H, El-Ghonelmy E, El-Haddad S. Impact of nutritional supple-mentation on treatment delay and morbidity in patients with head and neck tumors treated with irradiation. Nutrition. 1992; 8:13-18.

13. Isenring EA, Capra S, Bauer JD. Nutrition intervention is beneficial in oncology outpatients receiving radiotherapy to the gastrointestinal or head and neck area. Br J Cancer. 2004; 91:447-452.

14. Bauer JD, Capra S, Battistutta D, Davidson W, Ash S. Compliance with nutrition prescription improves outcomes in patients with unresectable pancreatic cancer. Clin. Nutr. 2005; 24:998-1004.

15. Odelli C, Burgess D, Bateman L, Hughes A, Ackland S, Gillies J, et al. Nutrition support improves patient outcomes, treatment tolerance and admission characteristics in oesophageal cancer. Clin Oncol. 2005; 17:639-645.

16. Dept of cancer epidemiology, NICRH. Cancer Registry Report 2008-2010, NICRH

17. Lemarie E, Goldwasser F, Michallet M, De Montreuil, Claude B, Hebuterne X. Prevalence of malnutrition in lung cancer patients: a one-day survey: P1-257. Journal of Thoracic Oncology August 2007; 2(8): S840-S841

18. Radbruch L, Elsner F, Trottenberg P, Strasser F, Fearon K. Clinical practice guidelines on cancer cachexia in advanced cancer patients. Aachen, Department of Palliative Medicinen/ European Palliative Care Research Collaborative; 2010.

19. Reeves GK, Pirie K, Beral V, Green J, Spencer E, Bull D. Cancer incidence and mortality in relation to body mass index in the Million Women Study: cohort study. BMJ 2007; 335 (7630): 1134

20. Bauer JD, Capra S. Nutrition intervention improves outcomes in patients with cancer cachexia receiving chemotherapy - a pilot study. Support Care Cancer 2005 Apr;13(4):270-4. Epub 2004 Dec4.
21. Burden ST, Hill J, Shaffer JL, Campbell M, Todd C. An unblinded randomised controlled trial of preoperative oral supplements in colorectal cancer patients. J Hum Nutr Diet 2011; 24: 441-448.

22. Ovesen L, Allingstrup L, Hannibal J, Mortensen EL, Hansen. OP, Effect of dietary counseling on food intake, body weight, response rate, survival, and quality of life in cancer patients undergoing chemotherapy: a prospective, randomized study. J Clin Oncol 1993; 11:2043-2049.

23. Elia M, Van Bokhorst-de van der Schueren MAE, Garvey J et al. Enteral (oral or tube administration) nutritional support and eicosapentaenoic acid in patients with cancer: a systematic review. Int J Oncol 2006; 28: 5-23.

24. Baldwin C, Spiro A, McGough C et al. Simple nutritional intervention in patients with advanced cancers of the gastrointestinal tract, non-small cell lung cancers or mesothelioma and weight loss receiving chemotherapy: a randomised controlled trial. J Hum Nutr Diet 2011; 24: 431-440

25. Dintinjana RD, Guina T, Krznari Z, Radi M, Dintinjana M. Effects of nutritional support in patients with colorectal cancer during chemotherapy. Coll Antropol 2008; 32: 737-740.

26. Dintinjana R, Guina T, Krznari Z. Nutritional and pharmacologic support in patients with pancreatic cancer. Coll Antropol 2008; 32: $505-508$

27. Brown L, Capra S, Williams L. A best practice dietetic service for rural patients with cancer undergoing chemotherapy: a pilot of a pseudo-randomised controlled trial. Nutr Diet 2008; 65: $175-180$.

28. Davidson W, Ash S, Capra S, Bauer J. Weight stabilisation is associated with improved survival duration and quality of life in unresectable pancreatic cancer. Clin Nutr 2004; 23: 239-247.

29. Isenring E, Zabel R, Bannister M, Brown T, Findlay M, Kiss N, et al. (2012) Updated evidence based practice guidelines for the nutritional management of patients receiving radiation therapy and/or chemotherapy. Nutrition and Dietetics 2013 (DOI: 10.1111/ 1747-0080.12013). 